University of Windsor

Scholarship at UWindsor

2014

\title{
Conversations About Education: Professional Development through a Multi-Epistemic Lens
}

\author{
Roland Karen \\ University of Windsor \\ Julia Colella \\ University of Windsor \\ Blessing Igbokwe \\ University of Windsor
}

Follow this and additional works at: https://scholar.uwindsor.ca/educationpub

Part of the Education Commons

\section{Recommended Citation}

Karen, Roland; Colella, Julia; and Igbokwe, Blessing. (2014). Conversations About Education: Professional Development through a Multi-Epistemic Lens. Teachers and Teaching: Theory and Practice, 20 (4), 483-498.

https://scholar.uwindsor.ca/educationpub/17

This Article is brought to you for free and open access by the Faculty of Education at Scholarship at UWindsor. It has been accepted for inclusion in Education Publications by an authorized administrator of Scholarship at UWindsor. For more information, please contact scholarship@uwindsor.ca. 
Conversations About Education:

Professional Development through a Multi-Epistemic Lens

Karen Roland, Julia Colella, and Blessing Igbokwe Faculty of Education, University of Windsor Windsor, Ontario, Canada 


\begin{abstract}
This study involves the program evaluation of the Conversations About Education pilot, developed as a community collaboration to offer professional development involving participants from a Faculty of Education, local school partners, and community organizations offering programming to Newcomers to Canada. The program sought to provide a collective forum where educational issues could be examined and discussed through a multi-epistemic lens. During the program events participants were encouraged to share their personal perspectives of the classroom experience, and together discuss the implications that lived/life experience has on confronting bias in teaching. The evaluation of the pilot program employed a qualitative approach involving two focus group sessions; each focus group session used semi-structured questions to explore participants' perceptions of their experiences. The outcomes of the pilot program evaluation were found to include processes that promoted community-building, as well as the professional development of teaching professionals. This pilot program may provide an exemplar for teacher education programs to use to support similar initiatives to bring together educators in a community building activity to explore, share and learn about the world and themselves, and in this process, support critical pedagogical approaches to teaching and learning to contest cultural hegemony in classrooms and schools.
\end{abstract}

Keywords: teacher education, reflective practice, professional development, community of practice, knowledge communities 


\section{Conversations About Education: Professional Development through a Multi-Epistemic Lens}

Increasing immigration rates and demographic shifts have made a significant impact on the Ontario educational system - Ontario classrooms may be characterized as highly culturally and linguistically diverse. However, as Dlamini and Martinovic (2007) have purported, this level of diversification in the classroom does not extend to the members of the teaching profession. Given this, we would suggest that Faculties of Education have a responsibility to develop and promote community building strategies: to build communities of practice to "collectively redefine practice" as well as, knowledge communities "to improve individual practice" (Seaman, 2008, p. 277) within teacher education. These strategies would not only support cultural and linguistic differences in educational practice, but also, work to address the challenges and barriers that culturally diverse teacher candidates may face in teacher education field practicum settings.

To enhance social justice and equity, educational approaches that ensure equal access to learning, and greater equity in the classroom for diverse learners, are required (Hackman \& Rauscher, 2004). There is an urgent need to address the imbalance between the demographic profile of the student teacher (teacher candidate) population, and that of associate (host mentor teachers) teachers in practicum classrooms (Dlamini \& Martinovic, 2007). This has implications for teacher education programs, particularly in response to the findings of an environmental scan conducted in 2007 at a Southwestern Ontario Faculty of Education, in which the following issues were identified as potential barriers that culturally and linguistically diverse teacher candidates may face in their field practicum classrooms: 
- Issues can be culturally specific primarily involving the associate teacher and the classroom students;

- cultural issues may reside within the mind-set of the associate teacher around persons of difference;

- the impact of the power-differential in the associate teacher/teacher candidate relationship may be significant - the associate being perceived as the judge in the classroom with no room for negotiation; and

- that the inequity and bias that is experienced by minority students is complex and may be experienced on many levels and gradients (including differences among minority groups). Furthermore, there is a need to critically and directly examine the topic of racism in a constructive manner to encourage understanding and appreciation for the intrinsic value of cultural and linguistic contributions to the classroom (Solomon \& Rezai-Rashti, 2001). Therefore, as educators and 'agents of change' we believe that it is essential for teachers and teacher educators to: engage in reflective practice, challenge hegemony and stereotypical attitudes, and, promote and protect social justice and equity within an educational community of practice. The Conversation About Education pilot program supported critical pedagogical approaches to teaching and learning to contest cultural hegemony in the classroom given our belief that the educational community may benefit from sharing knowledge from various perspectives to keep abreast of the ever-changing cultural diversity in classrooms and the educational community.

Therefore, this study is not specifically relevant for Canadian educators only. Although it utilized participants within a Canadian community, not all participants were Canadian. Thus, this study demonstrates how a local community came together to share experiences and insights with 
one another from various backgrounds. Further, teachers, educators, and students bring to the classroom experience preconceptions based on their own lived experience. This program allowed for the exploration and discussion of these pre-conceived ideas through a multi-epistemic lens.

In this paper we will first describe a strategic initiative developed at a Southwestern Ontario Faculty of Education that attempted to create a collective forum where educational issues could be examined and discussed through a multi epistemic lens, to promote engagement in reflective practice through the processes of storytelling and counter-storytelling (Ladson-Billings \& Tate, 1995; Bell 2010), as a means of challenging hegemony and stereotypical attitudes. Following this we will discuss the qualitative evaluation of the pilot program itself.

\section{The Pilot Program - Conversations About Education}

The Conversations About Education pilot program was developed as a strategic community building initiative that invited members of a Faculty of Education (teacher candidates, faculty/staff), school partners, and members of local agencies supporting Newcomers to Canada, to work together to 'reconstruct' and transform the educational community. This pilot project, as a community-building collaboration, sought to offer an opportunity for professional development for participants as members of the broader educational community. In doing so, the pilot program embraced the capacity of narrative to render personal and social lived/life experiences as meaningful and relevant (Connelly \& Clandinin, 1990), in a multi-epistemic cultural context. This was done purposefully to create a shift in understanding as participants listened and shared experiences (Huber, 1999, p. 19) to "attempt to give voice to tacitly held personal knowledge....without abandoning the particular, the contextual, and the complex..." (Conle, 2000, p. 51). To this end, during the program events, a collective forum was created in which to share personal perspectives/stories of the classroom experience, and together, discuss 
the implications that lived/life experience has on confronting bias in teaching. Through this initiative, it was hoped that participants would do what Connelly and Clandinin contend is "to enter a professional knowledge landscape is to enter a place of story" (1999, p. 2).

\section{Theoretical framework - Conversations About Education pilot program.}

A critical theory framework utilizing counter-storytelling as an opportunity to name one's reality (Ladson-Billings \& Tate, 1995) to elicit multi-epistemic perspectives was used to provide participants with a voice. As Bell suggests, "stories operate on both individual and collective levels, they can bridge the sociological, abstract with the psychological, personal contours of daily experience" (2010, p. 16). In this storytelling context it is also important to consider that education is not neutral, and that examining the political nature of education may expose the oppressive power of Eurocentric knowledge (Kincheloe, 2005), and why, as Bourdieu (1985) purports, schools are able to reproduce the culture of certain groups at the expense of others. The Conversations About Education pilot program, as praxis, what Kincheloe (2008) describes as "the process of action-reflection-action," was developed in an effort to contest what he further contends is the "deskilling of teachers" to "low-level functionaries in the education workplace" (p. 124). Thus, during the pilot program participants were encouraged to share their personal perspectives of the classroom experience, and together, discuss the implications that multiepistemic perspectives, based on personal lived/life experience, has on confronting bias in teaching.

\section{Community building.}

Teachers as members of the broader educational community, bring more than professional training with them into the classroom - teachers are comprised of their culture, their education (international or locally trained), and their lived-experience. Pre-conceived notions and 
stereotypical views of diverse cultures and languages may be addressed through collective opportunities to problem-solve, collaborate, and dialogue to develop mutual understanding and a 'sense of community' amongst members. This can ensure that community members and new teachers are seamlessly integrated into the profession of teaching. Furthermore, this may also reduce occupational stress levels as all involved will feel valued and respected as contributing members of the community (Adams, 2009). Through the interaction of educators, particularly, associate teachers and teacher candidates, pre-conceived ideas might be addressed, creating a climate that supports the inclusion and valuation of multi-epistemic perspectives. This exchange of knowledge may be equated to the creation of a 'teacher knowledge community'.

Effective community building ensures reflective dialogue as members of the community talk about their circumstances and the unique challenges they face based on their own lived experience (Kruse, Seashore \& Bryk, 1994). This de-privatization of practice, where teachers share teaching methods and philosophies, collective focus on student learning, and collaborative opportunities to work together to improve their practice in every aspect, may provide teachers with the opportunity to "... affirm their common values concerning critical educational issues, and in support of the collective focus on student's learning" (Kruse, Seashore \& Bryk, p. 4).

The importance of community building is highlighted in the wake of an increased call for accountability in the teaching profession, and the desire of school boards to improve teachers' effectiveness with professional learning communities (PLC) (Thessin \& Starr, 2011). Models of community building have been fashioned around the PLC prototype, emphasizing professional development through collaboration;collaboration that encompasses much more than relationships but also an intensive interaction engaging educators in opening up their beliefs and practices to investigation and debate (Katz \& Earl, 2010). Katz \& Earl further opine that “...this kind of 
collaboration allows people to address tough problems of teaching..., build commitment through group understanding ..., solve issues of mutual concern ..., and spread innovations beyond individuals and single sites ...”(p.30).

As stated by Adams (2009), "...the idea is that you have this collective intelligence" (para. 8) where colleagues are able to share best practices and work to reach students in new ways. Community building through collaboration fosters sharing, intergroup dialogue, and relationship building; consequently, former resistance and reluctance to discuss and resolve conflicts may be eliminated and pre-conceived biases can be addressed. This process involves the development of teaching professionals by removing isolation and fostering peer collaboration.

\section{Professional development.}

Professional development, in any field of study, is vital as it allows individuals to continuously update, revise and reflect upon current practices. "Professional growth often depends not merely on developing new ideas or theories of action, but on eliminating or modifying those old ideas that have been shaping behaviour" (Osterman, 1990, p. 135). Professional development workshops provide teaching professionals with opportunities to explore ideas, learn from others' experiences, and in some instances, shift their point of view regarding educational issues and topics. This community of practice provides reciprocal learning and professional development for the novice and the experienced teaching professional.

Professional development workshops that invite teacher candidates, teachers from the field, as well as Internationally Educated Teachers, allow professionals to collaborate as members of the broader educational community. Knowledge that is gained is done so through 'cooparticipation in practice' with competent others, in what we would suggest is a 'community 
of practice' (Roth \& Boyd, 1999). Walkington (2010) reveals that, "in the past few years the notion of integrating professional experience has received heightened attention with the broader realization of the benefits that can be accrued to both university students and the partners who host learning opportunities" (p. 177). Through this, it is evident that the outcomes can be beneficial for all parties involved (students and professionals). Moreover, "Teachers break the isolation of their world and become a part of an intellectual community: finding out that they can learn from their peers, and in so doing become members of a collaborative group" (Lieberman \& Mace, 2009, p. 469).

A critical aspect of professional development is shared knowledge, “...Teachers authentically share their stories of practice in safe places - what may be referred to as 'knowledge communities' to make their personal practical knowledge explicit to themselves and to others" (Olson \& Craig, 2001, p. 668). As aptly noted by Dei, James, Karumanchery, Wilson \& Zine, 2000, "the production of knowledge from multiple sites and diverse cultural bases must form the fundamental grounds upon which we begin to develop pedagogy in a global, postmodern, and diasporic society" (p. 172). The Conversations About Education pilot program sought to develop a knowledge community amongst teacher candidates, faculty members, experienced teachers and administrators and educators who are Newcomers to Canada so that through this program, all involved would be able to participate in professional development based on the notion of shared knowledge. Classroom teachers are often faced with challenging situation that ranges from students' discipline, to curriculum and lesson planning, addressing controversial topics, dealing with parents or the professional community. Providing educators with the opportunity to share knowledge may lead to greater intercultural literacy amongst these professionals, including enhanced understanding gained from reflecting on the multi-epistemic 
knowledge and experiences of others in the education community. As a professional development opportunity, the Conversations About Education pilot program was utilized to provide positive outcomes for teaching professionals regardless of their level of experience, by challenging individuals to reflect on their current practice, as well as explore the implementation of new ideas.

The following Conversations About Education events were hosted by the Southwestern Ontario Faculty of Education: 'Creating a Community in Your Classroom'; 'Permission to Disagree'; and, 'Restorative Justice in our Schools: Principles \& Practices'. The format of each program event included a guest lecturer speaking about a relevant educational issue, followed by an interactive discussion session - guest speakers were requested to provide a set of discussion questions with which to facilitate small group discussions. Participants in these program events were members of the broader educational community and included: teacher candidates, associate teachers, school administrators, Newcomer to Canada teaching professionals, and Faculty of Education instructors and administrators. The event presenters used narratives and shared other people's lived experiences to draw participants out and to encourage them to talk about their own life/lived experiences drawing on the principle that “...people's stories to live by have moral, emotional, and aesthetic qualities..." (Connelly \& Clandinin, 1990, p. 113).

\section{Creating a community in your classroom.}

“A learning curriculum [originated by Lave and Wegner] is a field of learning resources in everyday practice viewed from the perspective of learners. A teaching curriculum, by contrast, is constructed for the instruction of newcomers" (Lave \& Wenger, 1991, p. 114). Similar to a community of practice, the learning curriculum allows individuals to come together to share what was learned in their everyday practice. Seaman (2008) states that theories of community 
building, both as a 'community of practice' as well as 'knowledge community' are group efforts to improve professional practice. And while there are similarities, there are also differences between these theories of community. The purpose of a community- of- practice has been purported to be to, “...develop members' capabilities; to build and exchange knowledge” (Wenger \& Snyder, 2000, p. 142), and that this involves engagement and learning opportunities for all community members. Therefore, the development of a community of practice is an opportunity to actively share experiences and knowledge in creative ways, to engage in processes of reflection and co-learning. However, in terms of the objectives of the Conversations About Education pilot program, there was greater alignment with the theory of community building as the development of 'knowledge communities' which Seaman (2008) describes as opportunities for members to "share their personal practical knowledge as a way of reflecting, a way of knowing, and a way of bringing meaning to others' stories....contributions from members of a knowledge community help story and re-story experiential narratives while shaping their meaning" (p. 272). Furthermore, Seaman shares that while "communities of practice and knowledge communities are about developing and sharing knowledge"(p. 272), the difference lies in the purpose of the group; a community of practice is "informally bound by what members do and what they know" whereas knowledge communities are "informally bound by what they know" (p. 277). Although both aspects of community were relevant in that the participants in the pilot study were informally bound by their membership in the broader educational community along with a shared belief of learning as a social process, we would suggest the pilot program, was more closely aligned with the development of a knowledge community in that it used narratives, stories and counter-stories to foster reflective practice to collaboratively construct knowledge (Seaman). 
The first event in Conversations About Education pilot program was facilitated by a Child and Youth Worker (CYW) with a local school board. Using personal stories and experiences to illustrate his point, he focused his talk on the importance of building strong and trusting relationships with students, and how these relationships build community, not only in the classroom, but also within the school community. Participants were divided into small discussion groups and shared perspectives concerning what they felt, based on their own experiences as educators, were supportive approaches to effectively engage students in the school community. Each group was also provided with a series of questions centering on strategies to create community in the classroom such as, "What is the most supportive approach to dealing with disengaged students?”

\section{Permission to disagree.}

Scholarship, from a critical theory perspective, must embed the voice of participants and provide the opportunity to claim and name one's reality - in effect, to present counterstories (Ladson-Billings \& Tate, 1995). These counterstories, as initial steps towards social justice, influence both teller and listener, and challenge meritocracy. We believe that as social justice educators there is a compelling need to engage in the process of critically examining societal rights and responsibilities, both as individuals, and as members of society. During the second pilot program event, small group discussions utilizing a case study approach, were used to challenge participants to critically examine human rights cases recently brought before the courts in Canada. This resulted in lively discussions about the conflicts of rights and freedoms that affect everyone who lives in a democracy, and the need for educators to be at the forefront of preparing citizens to take an active role in democratic processes. 
The case studies presented were based on situations in which 'competing rights' were evident, and were specifically selected because a decision could not be made using a simple right-versus-wrong response. To promote critical thinking in the classroom and beyond, participants were encouraged to critically engage, from their personal epistemological stance, with each of the case study situations, and to discuss: 1) Why is such a policy in place? What is the purpose of the policy/rule in question? 2) Does this policy/rule work? and, 3) What else will happen? What are the unanticipated results/outcomes? These discussions provided participants with the opportunity to react, to critically analyze 'real-life' situations, and to acknowledge a nuanced understanding of the cases presented, based on the multi-epistemic perspectives shared.

\section{Restorative justice in our schools: Principles \& practices.}

Restorative justice has roots with the Aboriginal peoples of North America, the Maori of New Zealand, and the peoples of Japan and Africa. The focus of restorative justice is accountability, reparation, and restoration (Cormier, 2002). In Ontario, the Ministry of Education, under the Safe Schools Act (Bill 81), required that school boards actively seek approaches to, "increase respect and responsibility.....and [to] set standards for safe learning and safe teaching in schools" (2000, p.1). The third and final Conversations About Education program event provided an introduction and overview of restorative justice and restorative practices in our schools.

To model a restorative justice classroom practice, participants were first assembled into a circle seating arrangement, and then provided with a 'speaking stone' to communicate with each other. The event began by asking participants to introduce themselves, and this was followed by a rich discussion about why and how restorative justice and restorative practices are effective and socially responsible strategies to use in managing conflict at both the classroom, as well as the 
school level. The guest speaker, a high school administrator, shared with participants the value of this approach as means of promoting and healing relationships, facilitating co-operation, and leading to collective resolution as a means to resolve conflicts and restore relationships. The central discussion question presented to participants asked them, as educators, to reflect upon, and to consider, "If punishment wasn't an option, what would you do?" and "What is your capacity to implement restorative practices at the school, classroom, or community level?"

Following the Conversation About Education events, a program evaluation of the pilot program was conducted to develop a better understanding of the project outcomes, and to explore participants' perspectives of their experience during the events. The next section of this paper presents the program evaluation of the pilot project, followed by a description of the study methods and findings.

\section{The Program Evaluation of the Conversations About Education Pilot Program}

Research conducted by Larson and Goebel (2008) suggests that co-learning opportunities developed through a partnership between the school community and teacher education programs may facilitate the important theory-to-practice connection for teacher candidates. Furthermore, reflective practice is a process which promotes professional growth through change, involving not only reflective practice, but also agency - the ability to take action and create change (Osterman, 1990). She further states that, "through reflection, professionals develop ideas about how to do things more effectively, and they transform these ideas into action" (p. 145). This reflective aspect of professional learning has implications for all members of the educational community in terms of the promotion of organizational leadership and educational reform brought about through processes that foster critical thinking and analysis. Osterman contends 
that reflective practice must emphasize the importance of theory and ideas, as well as experience and reflection:

...reflective practice challenges educators to become personally and actively involved in the creation of better schools. It challenges them to examine the ideas which shape schools and to actively engage in reconstructing that reality. Without restructuring the underlying mindscapes, restructuring of schools will not occur (p. 151).

Critical educators engage their students in exposing and challenging hegemony, and it is suggested that adhering to a critical pedagogical perspective is an exemplar of social action in an educational context - working to transform the reality in the classroom, and at the school level (Montaño, López-Torres, DeLissovoy, Pacheco, \& Stillman, 2002). The symbolic processes of assumptions about racialized groups are fed by the stereotypical attitudes and behaviours of educators; educators become the 'institutional agents' in transmitting social and cultural norms (Solomon \& Rezai-Rashti, 2001). Therefore, as these scholars have suggested, we believe that it is imperative that educators become social activists, re-constructivists by revising, rather than reproducing the status quo.

The program evaluation of the Conversations About Education pilot program sought to investigate a contextualized understanding of the perceptions and attitudes and knowledge shared by the participants, their multi-epistemic perspectives of what they know and what they have experienced in their lives. Experience is the means by which individuals are able to transform meaning through a process mediated by their own personal perception - the reflective process of learner generating meaning through introspection and reflective practice (Webb, 2003). This is in accordance with what Osterman (1990) contends is the critical role that universities play in 
fostering reflective practice in teacher education - a critical component in the development of a community of practice in teacher education.

\section{Method - Program Evaluation}

During the Conversations About Education pilot program it was vital to build a knowledge community with which to enhance understanding amongst the participants as they reflected on the multi-epistemic knowledge and experiences shared by others. The program evaluation of this pilot was done to investigate whether the participants were able to engage in reflexive practice, feel that they were a contributing member of a knowledge community, and gain some form of professional development. The results of this evaluation will allow the researchers to determine if the objectives of the program were met, and to provide recommendations for future modifications and enhancement when offering the program.

\section{Qualitative research strategy.}

A qualitative research strategy was selected for the program evaluation of the pilot program given that it was so closely aligned with the theoretical framework of the research inquiry. "Qualitative researchers influenced by critical theory are interested in either how social values and organization get reproduced in schools and other educational institutions, or how people produce their choices and actions in the society" (Weiler as cited in Bogdan \& Biklen, 1998, p. 21). However, of great importance to this study was the need, as critical theorists, to engage in processes that empower and transform social inequities (Barone, 1992); the approach of this study was closely aligned with what Barone refers to as critical storytelling, a process of "studying the stories of others and criticisms of their own....confronting portraits of storytellers at work" (1992, p. 143).

\section{Focus groups.}


The program evaluation of the Conversations About Education pilot program employed a qualitative approach utilizing focus group sessions to investigate a contextualized understanding of the perceptions and attitudes and knowledge shared by the participants. Rescher (2003) states:

Knowledge claims can be regarded from two points of view, namely, internally and committally, subject to an acceptance thereof as correct and authentic, and externally and detachedly, viewed from an 'epistemic distance' without the commitment of actual acceptance, and seen as merely representing purported knowledge (p. xiv).

These perceptions and attitudes, the multi-epistemic perspectives of what people know, or understand themselves to know, "is simply the sum total of the answers they [people] offer to the questions they can resolve" (Rescher, 2003, p. xv). The focus group sessions used semistructured questions to explore participants' perceptions of their experience during the pilot program.

\section{Participants.}

A purposive sampling method was used to invite the approximately 50 participants who had attended one or more of the three Conversations About Education pilot program events; individuals were contacted via E-mail and asked to volunteer to participate in a focus group session to evaluate the pilot program. Three focus group sessions were scheduled; however, the final session was subsequently cancelled. Six individuals responded to confirm their participation in the focus group sessions; however, ultimately three individuals participated in the two focus group sessions held.

\section{Data collection.}

Each focus group session was audio recorded and transcribed (the audio recordings were erased after transcription). As well, researchers took field notes during each focus group session. 
At the conclusion of each focus group session, the primary researcher conducted a membercheck process to ensure the accuracy of the interpretation of the participants' meaning.

\section{Data Analysis}

\section{Focus group questions.}

The purpose of the focus group sessions were to provide the research team with a clearer understanding of the Conversations About Education participants' perceptions and experiences, as educators. The focus group sessions used the following semi-structured questions, asking participants to share:

- Whether or not participation in the pilot program assisted them to develop better knowledge about education in Ontario classrooms to use as a basis for future decisions/actions in their teaching practice;

- whether or not they felt they had gained new ideas to implement in their teaching practice;

- whether or not participation in the pilot program had an impact on them professionally in terms of reconsidering their views towards the topic(s) presented;

- whether or not they felt their experience in the pilot program provided them with the opportunity to update their professional skills;

- whether or not they had learned a new approach to teaching; and

- whether or not participation in the pilot program had an impact on their development personally in terms of presenting themselves as teaching professionals with a rich background of knowledge and experience to contribute to the teaching profession.

The outcomes of this research inquiry were based on the analysis of the perceptions and insights shared by participants during the focus group sessions to allow for a deeper 
understanding of all of the data collected: focus group transcripts, researcher field notes, and member-check summary. Data analysis was comprised of two stages: concurrent analysis which was done throughout the study; and formal analysis based on an in-depth analysis of all the data collected. The concurrent (field) analysis was based on the research questions, as well as the researcher field notes. The formal data analysis required the researchers to critically analyze all of the data collected as a basis for developing conceptual categories of data coding (Bogdan \& Biklen, 1998).

\section{Results}

The results of the program evaluation, from the data collected during the focus group sessions, were conceptualized in two major categories: 1) community of educators, and 2) professional development.

\section{Community of educators.}

Within the category of 'Community of Educators' the following concepts emerged: networking, community-building, and the opportunity to share diverse ideas.

\section{Networking.}

The concept of networking was seen as a positive aspect of the program. Participants reported that they enjoyed the fact that there were many other experienced teachers and administrators present during the events. Likewise, they also reported that they enjoyed interacting with teacher candidates from other instructional divisions. This was evident in the following focus group participant's statement:

It was wonderful to see other teacher candidates from different sections; I got to see [teacher] candidates from Primary/Junior, Junior/Intermediate, and Intermediate/Senior, and to know that a Principal from one of the schools was 
actually there [as well as] our Associate Dean [Pre-Service] was there too - this was really wonderful for me to experience... I am learning that you are right there beside me too [learning as well]. These are potentially people that I'll be working with some way, shape, or form, one day.

One of the focus group participants also indicated a positive reaction to the presence of Newcomers to Canada in the program events, "[it] made a difference [to me] that there were people there from the community." This focus group participant further expanded on this point, sharing that she felt that the opportunity to meet with a broad range of members from the educational community had provided her with even greater professional network.

\section{Community-building.}

Participants in the focus group sessions shared that during the Conversations About Education program they felt they were a part of an educational community, and furthermore, that this community was in fact non-threatening and non-judgmental. This was illustrated by a participant who shared that, "I felt that nobody was there to judge me." Participants also reported that they felt comfortable sharing their thoughts and ideas as contributing professionals, and that the interactive climate during the program events underscored the value and respect for everyone's opinions - "each of the workshops had [a sense of] mutual respect [for all participants] in them, even if people had differences of opinion, different ideas". These findings emphasize the value of multi-epistemic viewpoints as essential to the critical engagement of participants with the topics discussed.

\section{Sharing diverse ideas.}


Through the sharing of diverse ideas, participants were able to learn from each other. One participant stated that, "[Others] got to learn a little about me and my thoughts as another way of looking at it [the topic], and I got to learn from their [epistemic stance] too." Even though there were disagreements at times during the discussions, as one of the participant stated, “... [these] disagreements were healthy" as everyone was able to learn from each other. Moreover, participants stated that they felt that the program enabled them to critically examine issues pertaining to education.

\section{Professional development.}

Within the category of 'Professional Development' the following concepts emerged: teacher's role as social justice educator, teaching practice, learning: exploring ideas and observations, and shared knowledge.

\section{Teacher's role as a social justice educator.}

With respect to professional development in terms of a teacher's role as a social justice educator, findings from the focus group sessions revealed that participants identified part of a teacher's professional duty is to enact change in society. One of the focus group participant stated, "I can be a part of shaping things that I believe to be right because I believe as an educator, we are raising children." Additionally, participants indicated that they valued and embraced the notion of teaching professional, as that of a social justice educator.

\section{Teaching practice.}

Participants in the focus group sessions reported that they felt their teaching practice, with respect to the development of skills and professional ability was positively influenced as a result of their participation in the pilot program. They indicated that they were able to take with them practical skills and strategies that they could implement in their classrooms. This was 
supported by the following participant statement, "I felt like I had specific strategies that I can take into the classroom the very next day and use." Moreover, one focus group participant stated that the event she had attended allowed her the opportunity to receive her first practical look at differentiated instruction (DI), and that she felt that the facilitator had provided a "good model of skillful facilitation of [a] difficult conversation. Overall, participants suggested that their teaching practice was further developed through the opportunity to participate in the pilot program.

\section{Learning: Exploring ideas and observations.}

Focus group participants shared that the discussions held during the Conversations About Education program events allowed them to review and reconsider some of their views regarding disciplinary approaches and social justice issues in the classroom. Some even reported a shift in their viewpoint on certain issues - particularly discipline in the classroom. One focus group participant shared that discussing these issues with other educators allowed her to reconsider the ways in which she approached classroom management and discipline. Furthermore, this participant mentioned that hearing other people's approaches gave her new ideas to modify, as well as to build upon, her current professional teaching practice.

\section{Shared knowledge.}

Shared knowledge was a recurring theme reported by focus group participants. Participants indicated that they felt they were active members in sharing knowledge with their peers in an educational community. One focus group participant stated that, “...it was good to hear about peoples' experiences... because first-hand experiences are what you can learn the most from...you can read a textbook, you can go online and research, but hearing people's firsthand experience is what gives me the knowledge that I need to build on [as a teaching 
professional]." Another focus group participant shared that “... it was nice to hear people's exemplars... [this] gave me ideas of how I could use it." Also, participants stated that the content of the program events was meaningful and relevant to their professional practice.

\section{Discussion}

Participants reported that engagement in the pilot program events as members of a 'collective forum' to discuss educational issues, allowed them to nurture and develop a deeper understanding and respect for alternate viewpoints. Osterman (1990) contends that networking with other educators may be critical to the development of a community of practice in education, and we would suggest that the findings of this program evaluation support this claim. This points to the effectiveness of the program as a method of community building and as one in which, as Kruse, Seashore and Bryk (1994) suggest, reflective dialogue enables the respectful exchange of ideas.

In terms of professional development, focus group participants also shared their belief that as educators, they have an obligation to promote social justice and equity in schools. This was evident given their engagement in critically analyzing and reflecting on their own personal views, as well as those of others. Lieberman and Mace (2009) described the importance of an intellectual community as an effective means to combat professional isolation. This 'intellectual' sharing in a community also has practical benefits in terms of opportunities to observe educators model social justice theory in practice - praxis. Furthermore, participants in the Conversation About Education program indicated that although there were disagreements and differences of opinion at times during the discussions, diverse ideas were shared amongst the participants in a non-judgmental and safe environment. Disagreements were viewed as healthy, and the sharing of multi-epistemic viewpoints was seen as especially helpful to teacher candidates as new members 
of the teaching profession. This aligns with the stated benefits of community building as purported by Adams (2009) - that a forum like this increases “... problem-solving dialogue" and “... fosters a sense of community and teamwork" (para. 18).

\section{Limitations}

There were limitations which may have affected the results of this program evaluation. To begin with, there were three members of the faculty research team conducting the focus group sessions, and while every effort was made to create a safe and welcoming environment to elicit honest and frank response from participants, there may have been some initial feelings of reservation and intimidation on the part of the focus group participants. Another limitation may have been the fact that there were so few participants present at the focus group sessions - there were only three focus group participants in total; this limited the scope of data that the research team was able to collect. While there were diverse groups of individuals in each Conversation About Education program event, the participation in the focus group sessions did not reflect this diversity. Lastly, a recall effect may have been present for some participants since they were being asked to provide information regarding the Conversations About Education events which were held up to six months earlier. This may have influenced the accuracy of their perceptions and the information that they shared during the focus group sessions.

\section{Conclusion}

Participants who attended the program evaluation focus group sessions reported that they felt they had benefitted from their participation in the Conversations About Education pilot program. They indicated that the topics discussed during the program events were relevant and meaningful, and of importance to them, was the development of a sense of community in which they, as educational professionals with a range of experience, and diverse lived experiences, 
came together and engaged in thoughtful, reflective and respectful discussions. This aligns with Connelly and Clandinin's contention that, "educational research holds that humans are storytelling organisms who, individually and socially, lead storied lives" (1990, p. 2).

Furthermore, as Bell contends, storytelling can be viewed as a form of social action providing teachers with the opportunity to critically explore overt and implicit assumptions “...to develop strategies to teach knowledgably, conscientiously, and ethically in communities they often enter as privileged outsiders" (2010, p. 79). Through the storytelling approach during professional discussions, knowledge was shared, and current practices reflected upon. Furthermore, some participants suggested that given the value of this experience, particularly in terms of the 'professional empowerment' opportunity for beginning teachers that they would recommend that this program be included as a core component of professional learning in teacher education programs.

Therefore, we would suggest that the Conversations About Education pilot program proved successful in bringing together members of the broader educational community to participate in a collaborative learning forum to create a knowledge community. The outcome of this program appeared to have met the states goals through the development of a strategic initiative to address: 1) relationship building to create a 'knowledge community' in which educational issues were examined through a multi-epistemic lens; and 2) also providing professional development opportunities for teaching professionals focused on social justice issues and the implications of lived/life experience on confronting bias in the teaching profession. Not only did the program provide participants with new ideas that could be implemented in their classrooms, participation also provided an opportunity to reflect and shift their personal viewpoints regarding educational issues. 
The results of this program evaluation indicated that the participants reported positive experiences sharing with individuals from many backgrounds. Although this was a Canadian pilot program, we believe that it could be replicated in other countries. Participants reported learning from each other and that as individuals they were encouraged to re-evaluate their own teaching practice after reflecting on their shared experiences. Lastly, participation in such a knowledge community may promote social justice and equity, which is not only a goal for Canadians, but may be a desired outcome for citizens worldwide.

In conclusion, participants in the program evaluation of the Conversations About Education pilot program indicated that these events were opportunities to discuss social justice issues pertinent to education in a safe, welcoming, and non-threatening learning environment an educational knowledge community. Through their stories and discussions, participants shared that they were able to self-reflect on their own current educational practices, were exposed to multi-epistemic viewpoints, and were provided with resources to support them in the development of their professional practice. Similarly, engagement in a knowledge community allowed participants who attended the events to share experiences, such as practicum experiences for the teacher candidates, with others, while simultaneously reflecting on their own experience. We are hopeful that programs similar to this pilot program, hosted through teacher education programs, may work to support more occasions for educators to come together to create knowledge communities to explore, share and learn about the world and themselves, and that this may shift support for a critical pedagogical approach to contest the status quo of cultural hegemony in our classrooms and schools. 


\section{References}

Adams, C. (2009). The power of collaboration. Instructor, 119(1), 28-31.

Barone, T. E. (1992). Beyond theory and method: A case of critical storytelling. Theory into Practice, 31(2), 142-146.

Bell, L. A. (2010). Storytelling for social justice: Connecting narrative and the arts in antiracist teaching. New York, NY: Routledge.

Bogdan, R.C. \& Biklen, S. K. (1998). Qualitative research for education: An introduction to theory and methods. Needham Heights, MA: Allyn \& Bacon.

Bourdieu, P. (1985, June). The social space and the genesis of groups. Social Science Information, 24(2), 195-220.

Conle, C. (2000). Narrative enquiry: Research tool and medium for professional development. European Journal of Teacher Education, 23(1), 49-63.

Connelly, F. M. \& Clandinin, D. J. (Eds.) . (1999). Shaping a professional identity: Stories of educational practice. London, ON: Althouse Press.

Connelly, F. M. \& Clandinin, D. J. (1990). Stories of experience and narrative inquiry. Educational Researcher, 19(5), 2-14.

Cormier, R. (2002). Restorative justice: Promising beginnings. Research Summary, Corrections Research and Development, 7(5). Ottawa, Canada: Department of Public Safety and Emergency Preparedness Canada. Retrieved from http://www.restorativejustice.org/articlesdb/authors/4458

Dei, G. J. S., James, I. M. J., Karumanchery, L. L., Wilson, S. J., \& Zine, J. (2000). Removing the margins: The challenges and possibilities of inclusive schooling. Toronto: Canadian Scholar Press Inc. 
Dlamini, S. N. \& Martinovic, D. (2007). In pursuit of being Canadian: Examining the challenges of culturally relevant education in teacher education programs. Race Ethnicity and Education, 10(2), 155-175.

Hackman, H. W. \& Rauscher, L. (2004). A pathway to access for all: Exploring the connections between universal instructional design and social justice education. Equity \& Excellence in Education, 37, 114-123.

Huber, J. (1999). Listening to children on the landscape. In F. Michael Connelly \& D. Jean Clandinin (Eds.). Shaping a professional identity: Stories of educational practice (pp. 919). London, ON: Althouse Press.

Katz, S. \& Earl, L. (2010). Learning about networked learning communities, school effectiveness and school improvement. An International Journal of Research, Policy and Practice, 21(1), 27-51.

Kincheloe, J. L. (2005). Critical pedagogy primer. New York, NY: Peter Lang Publishing, Inc.

Kincheloe, J. L. (2008). Critical pedagogy primer $\left(2^{\text {nd }}\right.$ Edition). New York, NY: Peter Lang Publishing, Inc.

Kruse, S., Seashore, K. \& Bryk, A. (1994). Building professional community in schools. Madison, WI: Center on Organization and Restructuring of Schools, U of Wisconsin. Retrieved from http://www.learner.org/workshops/principals/materials/pdf/kruse.pdf Ladson-Billings, G. \& Tate, W.F. (1995, Fall). Toward a critical race theory of education. Teachers College Record, 97(1), 47-68.

Larson, W. C. \& Goebel, A. J. (2008). Putting theory into practice: A professional development school/university co-teaching project. Journal of the Scholarship of Teaching and Learning, 8(2), 52-61. 
Lave, J., \& Wenger, E. (1991). Legitimate peripheral participation in communities of practice. In R. Harrison, F. Reeve, A. Hanson, \& J. Clarke (Eds.), Supporting Lifelong Learning Volume 1 - Perspectives on Learning (pp. 111-126). New York, NY: RoutledgeFalmer. http://books.google.ca/books?hl=en\&lr=\&id=B0KmKtWdBJMC\&oi=fnd\&pg=PP1\&dq= $\underline{\text { Lave, }+\mathrm{J} .,+\% 26+\text { Wenger, }+ \text { E.+(1991).+Legitimate+peripheral+participation+in+communi }}$ $\underline{\text { ties }+ \text { of }+ \text { practice. }+ \text { In+R.+Harrison },+ \text { F. }+ \text { Reeve, },+ \text { A.+Hanson, },+\% 26+\text { J.+Clarke+(Eds. }),+ \text { Su }}$ pporting+Lifelong+Learning+Volume+1+\%E2\%80\%93+Perspectives+on+Learning\&ots $=$ SZyGA0CrPI\&sig=ht3QmrqAyIiK9dL62IGk5qpNFMA\#v=onepage $\& q \& \mathrm{f}=$ false

Lieberman, A. \& Mace, D. (2009). The role of accomplished teachers' in professional learning communities: Uncovering practice and enabling leadership. Teachers and Teaching: Theory and Practice, 15(4), 459-470.

Montaño, T., López-Torres, L., DeLissovoy, N., Pacheco, M., \& Stillman, J. (2002). Teachers as activists: Teacher development and alternate sites of learning. Equity \& Excellence in Education, 35(3), 265-275.

Olson, M. \& Craig, C. (2001). Opportunities and challenges in the development of teachers' knowledge: The development of narrative authority through knowledge communities. Teaching and Teacher Education, 17(6), 667-684.

Ontario Ministry of Education. (2000). Bill 81, Safe Schools Act. Retrieved from: http://www.ontla.on.ca/bills/bills-files/37_Parliament/Session1/b081ra.pdf

Osterman, K.F. (1990). Reflective practice: A new agenda for education. Education and Urban Society, 22(2), 133-152.

Rescher, N. (2003). Epistemology: An introduction to the theory of knowledge. New York: State University of New York Press. 
Roth, W. M. \& Boyd, N. (1999). Coteaching, as colearning, is praxis. Research in Science Education, 29(1), 51-67.

Seaman, M. (2008). Birds of a feather? Communities of practice and knowledge communities. Curriculum and Teaching Dialogue, $10(1 \&$ 2), 269-279.

Solomon, R. P. \& Rezai-Rashti, G. (2001). Teacher candidates' racial identity development and its impact on learning to teach. Toronto, ON: Canadian Race Relations Foundation.

Thessin, R. A. \& Starr, J. P. (2011). Supporting the GROWTH of Effective Professional Learning Communities Districtwide. Phi Delta Kappan, 92(6), 48-54.

Walkington, J. (2010). Teacher educators: The leaders in work-integrated learning. Asia-Pacific Journal of Teacher Education, 38(3), 177-180.

Webb, M. (2003). A Definitive Critique of Experiential Learning Theory. Unpublished doctoral thesis, Department of Organizational Behavior, Weatherhead School of Management, Case Western Reserve University, Ohio.

Wenger, E. C. \& Snyder, W. M. (2000). Communities of practice: The organizational frontier. Harvard Business Review, 78(1), 139-145. 


\section{Notes on contributors}

Karen Roland $(\mathrm{PhD})$

roland1@uwindsor.ca (519-253-3000 ex. 4288)

Dr. Karen Roland is the Acting Dean for the Faculty of Education, University of Windsor, Windsor, Ontario, Canada. Her areas of research interest include: social justice education, restorative justice in education, educational equity, teacher education, diversity and policy and administration.

\section{Julia Colella (MEd Candidate)}

Julia Colella holds a Master of Education degree from the Faculty of Education at the University of Windsor, Windsor, Ontario, Canada. She has recently been admitted to the Joint PhD in Educational Studies program at the Faculty of Education, University of Windsor. Her research interests include academic misconduct in higher education and student-centered learning.

\section{Blessing Igbokwe (PhD Student)}

Blessing Igbokwe is an Ontario Certified Teacher (OCT) currently completing the PhD program in Educational Studies at the University of Windsor, Windsor, Ontario, Canada. Her research interests include environmental education, GIS in environmental education, teacher education and special education. 